\title{
Prevention and treatment of trauma induced coagulopathy (TIC). An intended protocol from the Italian trauma update research group
}

\author{
Giuseppe Nardi ${ }^{*}$, Vanessa Agostini ${ }^{2}$, Beatrice Rondinelli Maria ${ }^{3}$, Grazia Bocci ${ }^{4}$, Stefano Di Bartolomeo ${ }^{5}$, Giovanni Bini ${ }^{6}$, Osvaldo Chiara ${ }^{7}$, \\ Emiliano Cingolani ${ }^{1}$, Elvio De Blasio ${ }^{8}$, Giovanni Gordini ${ }^{9}$, Carlo Coniglio ${ }^{9}$, Concetta Pellegrin ${ }^{8}$, Luigi Targa ${ }^{6}$ and Annalisa Volpi ${ }^{10}$ \\ *Correspondence: gnardi@scamilloforlanini.rm.it \\ 'Shock and Trauma Centre, S. Camillo-Forlanini Hospital, Roma Italy. \\ 2Department of Clinical Pathology, Transfusion Medicine Service, Bufalini Hospital, Cesena, Italy. \\ ${ }^{3}$ Department of Immunoemathology and Transfusion Medicine, S. Camillo-Forlanini Hospital, Roma, Italy. \\ ${ }^{4}$ Department of Intensive Care, Catholic University, Roma, Italy. \\ ${ }^{5}$ Department of Anesthesia and Intensive Care, Hospital and University, Udine, Regional Health Agency Emilia-Romagna, Italy. \\ ${ }^{6}$ Department of Anesthesia and Intensive Care, Bufalini Hospital, Cesena, Italy. \\ ${ }^{7}$ Emergency Department, General Surgery and Trauma Team Niguarda Hospital, Milan, Italy. \\ ${ }^{8}$ Department of Anesthesia and Intensive Care, Rummo Hospital, Benevento, Italy. \\ ${ }^{9}$ Emergency Department, Intensive Care Unit and EMS, Maggiore Hospital, Bologna, Italy. \\ ${ }^{10}$ Department of Anesthesia and Intensive Care, Maggiore Hospital, Parma, Italy.
}

\begin{abstract}
In recent years, a strong focus has been put on the need to assure early coagulation support in order to prevent and treat coagulopathy in patients with severe trauma, and to improve survival. Aggressive plasma administration with high plasma/ red blood cells ratio is increasingly used worldwide. However, plasma transfusion is associated with increased risks of multiple organ dysfunction syndrome (MODS), adult respiratory distress syndrome (ARDS) and infection, which may prolong hospital stay and the need for artificial ventilation. Moreover, in the majority of European hospitals plasma cannot be immediately available and therefore it has been reported a significant delay in coagulation support. This has lead to the proposal of using clotting factors as an alternative to plasma. However, strong evidence to define the best strategy is still missing, and the only published protocols are Institution-specific, thus depending on the local organization and the available resources. The Italian Trauma Centers Network (TUN) recently developed a treatment protocol aiming at shortening the interval before the onset of coagulation support and at reducing the use of plasma. We present this protocol-Early Coagulation Support (ECS) Protocol - and discuss its rationale. Its implications for the trauma-team workflow and hospital organization are also addressed. The ECS protocol must be considered as an integrated part of a comprehensive Damage Control Strategy. The impact of the ECS Protocol on blood products consumption, trauma mortality and morbidity as well as its financial aspects, will be strictly monitored by the TUN hospitals.
\end{abstract}

Keywords: Trauma, coagulopathy, transfusion, plasma, clotting factors, protocol, multicenter

\section{Background}

Haemorrhage is the principal cause of death in the first few hours following severe injury. Coagulopathy is a frequent complication of haemorrhage and may occur in up to $25 \%$ of patients, even before hospital admission [1]. In recent years, international guidelines [2] that aim at preventing and treating traumainduced coagulopathy (TIC), have been developed. However, due to the heterogeneous availability of haemocomponents and clotting factors in different countries and to the lack of sound data in the literature, there is not a widely agreed clinical strategy yet. Moreover, due to the aging population in western countries, elderly people with cardiovascular comorbidities and on antiplatelets agents or oral anticoagulants are increasingly represented. Therefore, a comprehensive protocol to treat the bleeding patients should also include strategies to quickly reverse the effect of these drugs.

Any strategy should rapidly tackle acute traumatic coagulopathy through the early replacement of clotting factors. Haemostasis is critically dependent on fibrinogen as a substrate for clot formation. Fibrinogen is the single factor which is more and earlier affected in case of TIC. Many bleeding trauma patients with TIC present with a depletion of fibrinogen below levels currently recommended for therapeutic supplementation [2]. In a recent study, hypotension, increasing shock severity (as measured by the base deficit) and high degree of injury (ISS $\geq 25$ ), were all associated with a reduction in fibrinogen levels [3]. Fibrinogen depletion is associated with poor outcomes and survival improves with the amounts of fibrinogen administered [4]. Plasma has traditionally been used as a source of fibrinogen. However, until few years ago plasma transfusion was not recommended in absence of a prolongation of PT or INR or fibrinogen decrease to less than $1.5 \mathrm{gr} / \mathrm{L}$. More recently, retrospective evidence from both military [5] and civilian [6] practice suggested improved outcomes in patients with massive bleeding after the adoption of a massive-transfusion protocol (MTP), including the early administration of highdose plasma therapy. Although the first reports based on the military experience suggested a 1:1 plasma/packed red

(C) 2013 Nardi et al; licensee Herbert Publications Ltd. This is an Open Access article distributed under the terms of Creative Commons Attribution License (http://creativecommons.org/licenses/by/3.0). This permits unrestricted use, distribution, and reproduction in any medium, provided the original work is properly cited. 
blood cells (PRBCs) ratio, more recent data, supported by thromboelastometry, have shown that a lower rate (i.e., 1:2) may be preferable [7]. There are several limitations on the use of plasma to prevent and treat TIC. Both Fresh Frozen Plasma (FFP) and pathogen-inactivated plasma (industrial purified plasma) need to be group matched, thawed and warmed before administration. Therefore, unless pre-thawed plasma is available, plasma transfusion cannot be started at the same time as universal PRBCs. A delay of 93' has been reported, [8] possibly explaining why the targeted plasma/RBCs ratio is reached only a few hours after starting treatment. During this interval fibrinogen level is likely to be lower than desired.

Plasma transfusion has also been associated with an increased risk of post injury MODS, ARDS and infections. These complications increase with the volume of transfused plasma [9]. The risk of transfusion related acute lung injury (TRALI) has been greatly reduced by avoiding the use of the plasma of women with pregnancy history [10]. In Italy the recent introduction of pathogen-inactivated plasma enabled to further minimize the risks of TRALI and virtually eliminate the risks of transmission of infective diseases. Although these measures are effective in reducing some of the adverse effects of plasma transfusions, recent data [11] show that in patients who require less than 6 Units of PRBCs, the complications related to plasma transfusion may overcome the benefits.

The balance between a rapid intervention to treat or prevent $\mathrm{TIC}$ and the risk related to unnecessary transfusion of plasma, is difficult to achieve. The use of coagulation factor concentrates have been proposed as the strategy to reduce and even avoid plasma transfusion in patients with significant bleeding. In the Austrian guidelines [12] fibrinogen concentrate is the first-line treatment. Two retrospective studies comparing data from Austrian Trauma Centres with the German Trauma (TR-DGU) registry, reported a significant reduction in platelet transfusion and a limited decrease in blood transfusion for bleeding patients treated with fibrinogen concentrate and prothrombin complex concentrate (PCC) who did not receive FFP during initial resuscitation $[13,14]$. Early coagulation monitoring with ROTEM was used to guide the administration of coagulation factors, starting immediately after patient admission. However, these results have not been confirmed by prospective controlled studies.

Although very appealing, the "plasma-free" strategy proposed by Schöchl [13] may not be easily adopted by Italian Trauma Centres as it requires thromboelastometry monitoring to be started straight on patient's admission and only few Italian hospitals can adhere to this requirement at the moment. Moreover it may imply the use of a rather high amount of fibrinogen with considerable related costs. Fibrinogen availability might also turn out to be problematic as fibrinogen is not commercially available in Italy and hospitals are supplied with limited amount on the base of a national drugs agency (AIFA) authorization.

The Steering Committee of the Italian Trauma Update
Network has recently developed a comprehensive treating protocol (Early Coagulation Support - ECS) to improve and homogenize the early treatment of trauma patients with significant bleeding and at high risk of massive transfusion. Compatibility with the resources currently available in the average Italian Trauma Centre is a key point of its rationale. Besides supporting coagulation and shorten the "time-to-treat" to effectively reduce the bleeding, the other main objective of the protocol is to limit the use of plasma in patients who are not likely to need it, in order to reduce plasma-related adverse effects.

\section{Methods}

The ECS protocol was developed by a multidisciplinary group of Anaesthetists, Haematologists, Surgeons and Intensive Care physicians involved in trauma care on daily basis. The Trauma Update Research Network (TUN) is an informal association of Italian Trauma Centres that jointly support and promote education and researches in Trauma Care sharing data and treatment strategies aimed to improve patients outcome. The ECS protocol is based on the available data from the current literature (as of August 2012). It is tailored on the current organization of the Italian Trauma Centres involved in the TUN, accounting for their limited financial and human resources. The TUN panel acknowledges the potential advantages of rapid (Point of Care) diagnostic tools to quickly identify coagulopathy and guide transfusion management as suggested by the European Guidelines [2]. However, the ECS protocol has been conceived to be feasible even when rapid diagnostic tools are not available, aiming to be a standard sustainable by all Institutions. The ECS protocol is presented in Table 1 and Table 2.

\section{Results and Discussion}

Based on the results of the Crash 2 study [15], the early administration of Tranexamic Acid (TA) to all patients with ongoing bleeding or at risk of significant bleeding is now standard care for the Trauma Centres of the TUN. According to the protocol, TA must be initiated on patient's admission after the collection of a blood sample for laboratory tests, cross matching and basal clotting profile. TA must be initiated within the first 3 hours after trauma. If for any reason, a patient has not received TA within this deadline, TA administration is not recommended. Initial administration of TA complies with the Crash 2 study protocol: initial dose of $1 \mathrm{gr}$, followed by a continuous infusion of the same dose of TA. If the viscoelastic monitoring allows to exclude ongoing fibrinolysis, further treatment may be avoided and the continuous TA infusion stopped.

The number of patients on antiplatelet or anticoagulation therapies is increasing. A retrospective cohort study of Trauma Centres, that submitted data to the National Trauma Databank (NTDB) from 2002 to 2007, demonstrated an increase in vitamin $\mathrm{K}$ antagonists (VKA) use in the general trauma population 
Table 1. The Early Coagulation Support (ECS) Algorithm.

* 10 Units of PTL $=2$ Units of single donor apheresis or 2

Units of buffy coats pool PTL.

** 1 Plasma Unit $=250 \mathrm{mls}$ of FFP or $200 \mathrm{mls}$ of ; if Apheris plasma is used 1 Unit $=500 \mathrm{mls}=2$ Units of FFP.

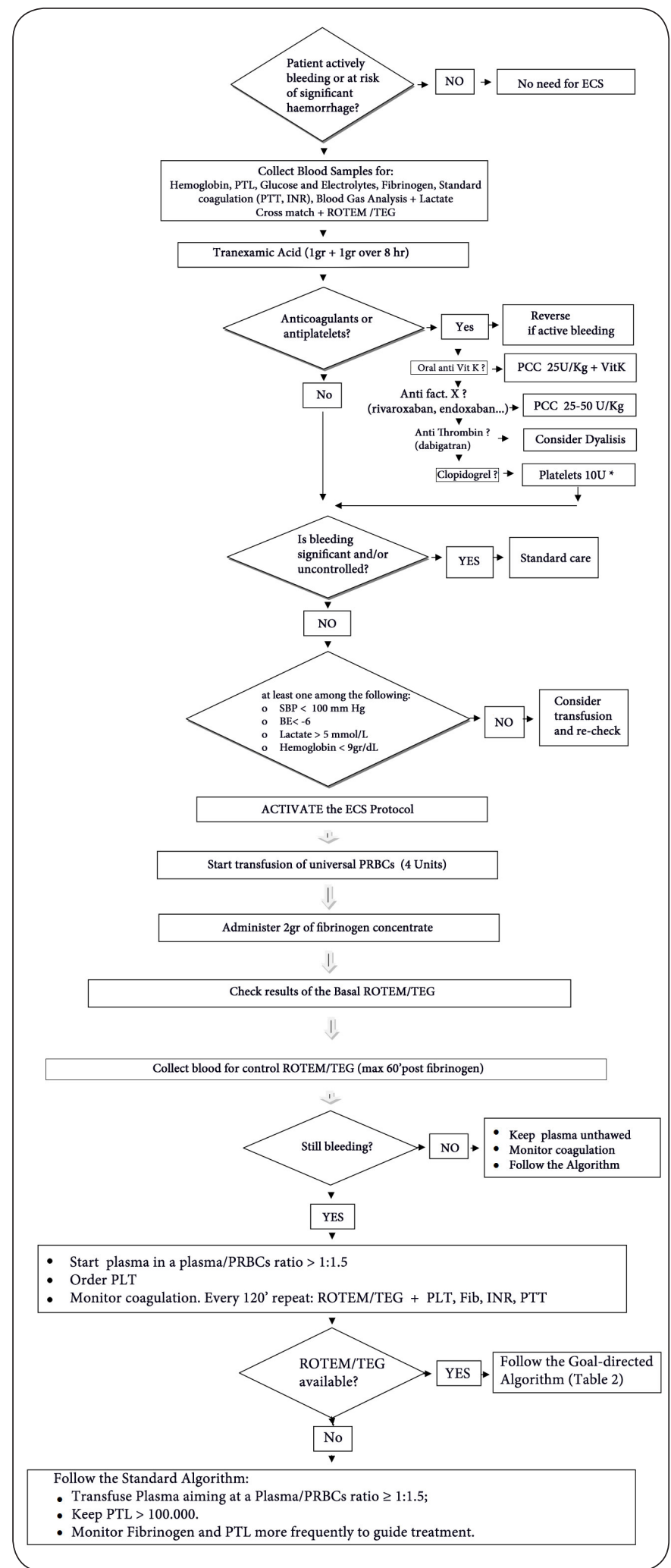

Table 2. Early Goal Directed Therapy based on the results of thromboelastometry monitoring.

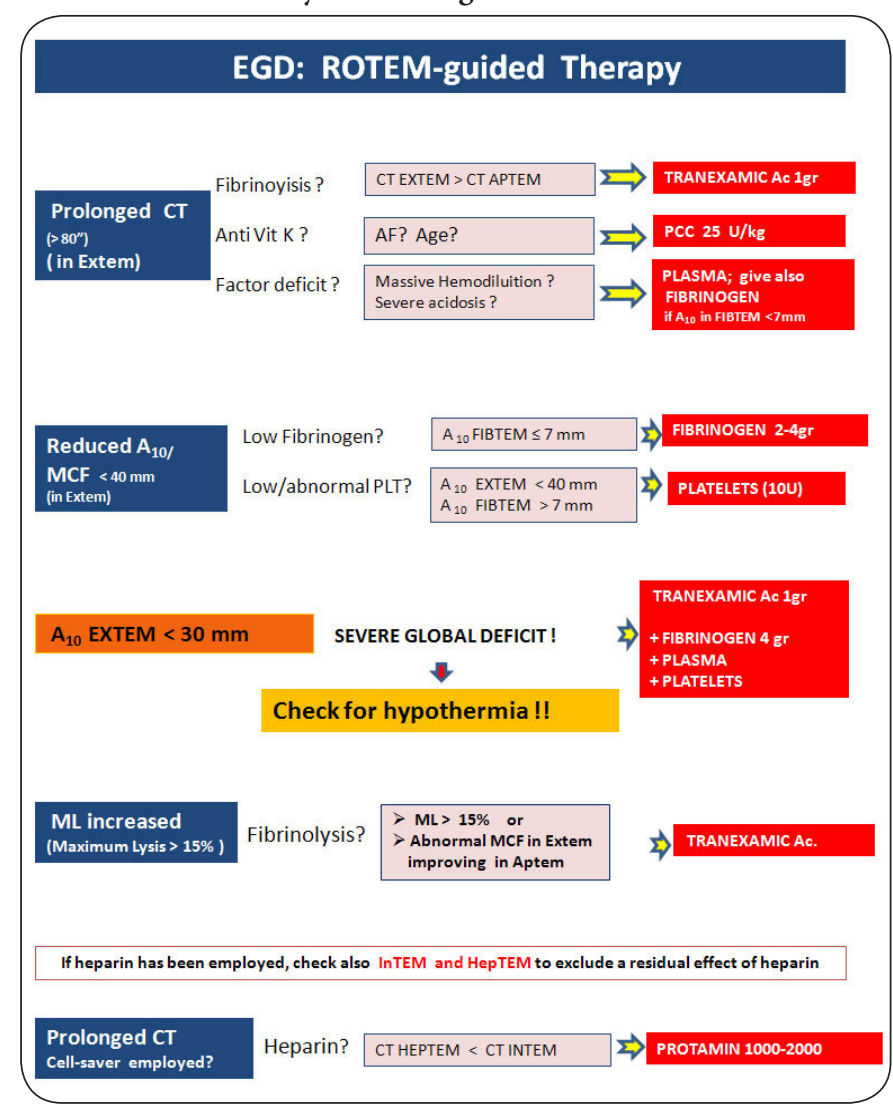

from $2.3 \%$ in 2002 to $4 \%(p<0.001)$ in 2006 . In patients older than 65 years the use of VKA increased from $7.3 \%$ to $12.8 \%$ in the same period $(p<0.001)$. Pre-injury VKA use is age-related with a sharp increase between the age of 45 and 70 years. Head trauma patients on VKA have a higher risk of intracranial haemorrhage. The younger patients on anticoagulants have a $50 \%$ higher mortality [16]. Recent guidelines recommend emergency anticoagulation reversal with PCC and Vitamin K in trauma patients with major bleeding or cerebral haemorrhage who are on VKA treatment [17-19]. PCCs are classified into three-factor and four-factor products. Three-factor concentrates have therapeutically useful levels of FII, FIX and FX; four-factor PCCs contain FII, FVII, FIX, FX together with protein $C$ and S. PCC is associated with a non negligible risk of thrombogenicity and disseminated intravascular coagulation (DIC) [20]. Eight retrospective studies have evaluated the outcomes associated with pre-injury anticoagulation therapy in patients admitted for traumatic head injury. In two of these studies the mortality was similar between the control and warfarin-treated patients; in the other six studies there was an increased mortality in the warfarin-treated group compare to the control group [21]. While mortality has been shown to increase in patients with traumatic brain injury on VKAs, data for trauma patients without brain injury are less 
Nardi et al. Journal of Anesthesiology and Clinical Science 2013,

http://www.hoajonline.com/journals/pdf/2049-9752-2-22.pdf

doi: 10.7243/2049-9752-2-22

Table 3. Anticoagulation reversal for bleeding patients on Vitamin K Antagonists (from FCSA recommendations [25], modified).

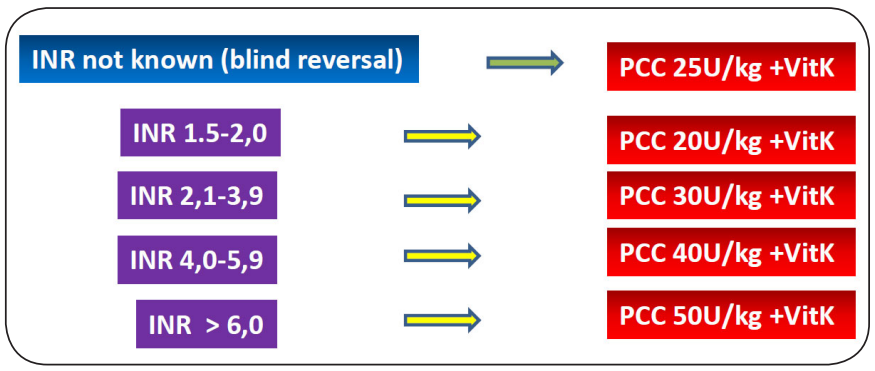

clear. "Time to correction of the INR" or "extent of correction of the INR" have been used as a surrogate outcome of clinical effectiveness rather than the cessation of clinical bleeding or mortality. Only one retrospective analysis could demonstrate that in trauma patients receiving warfarin, the addition of PCC treatment to FFP and vitamin $\mathrm{K}$ results in a quicker INR reversal. However, no outcome improvement was observed [22]. Not withstanding the lack of strong evidence, the TUN experts agreed to introduce in the protocol the use of PCC for the emergency reversal of vitamin $\mathrm{K}$ dependent oral anticoagulation. Therefore, in patients with significant active bleeding known to be on VKAs, immediate administration of PCC $(25 \mathrm{UI} / \mathrm{Kg})$ is recommended even before INR results. PCC treatment will be subsequently adjusted according to INR results $[23,24]$. The F.C.S.A. recommendations $[25]$ for the management of intracranial haemorrhage have been endorsed to guide treatment once INR is known (Table 3 ).

Recently several newer anticoagulants have been introduced in the clinical practice and a few more are under clinical development. Currently the oral thrombin inhibitor dabigatran etexilate (Pradaxa, Boehringer Ingelheim, Germany) is approved in the United States, Canada and Europe for the stoke prevention in atrial fibrillation and the oral factor Xa inhibitor rivaroxaban (Xareltro, Bayer AG, Germany) is approved for the prevention of venous thrombosis after orthopaedic surgery and for stroke prevention in atrial fibrillation.

These two drugs have a more balanced benefit/risk ratio and several advantages over warfarin: a rapid onset of action, a more predictable anticoagulant effect so that routine laboratory monitoring is not required, minor food and drugs interactions. Moreover they are expected to carry less hemorrhagic risks, particularly, less intracranial bleeding [26]. However a number of serious hemorrhages have been reported in the literature. On December 7, 2011, the FDA released a statement declaring that they were evaluating post-marketing reports of serious bleeding events in patients taking dabigatran, to determine if the rate of bleeding events was higher than what would be expected [27]. As novel agents, dabigatran and rivaroxaban, are relative unknown to the practicing community and there is little or no evidence to guide practical management when patients present with acute bleeding. Because of the short half-life of the newer agents observation and supportive care with immediate anticoagulant withdrawal is the preferred strategy in patients with minor or mechanically controlled bleeding. However when a life-threatening haemorrhage occurs, intervention with reversal agents might be warranted. Unfortunately neither plasma nor cryoprecipitate, are effective in reversing the anticoagulant effect of the new drugs [28]. A few studies have investigated reversal agents; all of these have used animal model or healthy human subjects to evaluate the role of different reversal drugs. The human studies focused on the effect of four-factor PCC on coagulation tests $[29,30]$ and demonstrated that high doses of 3-factors or 4-factors PCC are probably effective for the reversal of rivaroxaban, but not for dabigatran [31]. Dabigatran can be dialyzed, with the removal of about $60 \%$ of the drug over 2 to 3 hours, but data supporting this approach are limited and the potential use of dialysis in the context of severe trauma related bleeding is questionable [32]. The Italian Federation of Thrombosis Centres (FCSA) recently produced a consensus document suggesting the administration of 4 -factors PCC for the reversal of rivaroxaban in the one shot dose of $50 \mathrm{UI} / \mathrm{Kg}$ [33].

Antiplatelet drugs - mostly aspirin and P2Y-thienopyridine antagonists (clopidogrel, prasugrel, ticlopidine) - are prescribed for prophylaxis and treatment in patients with cardiovascular or cerebrovascular diseases. These drugs are associated with an increased risk of intracranial haemorrhage. Drugs of both classes irreversibly inhibit platelets function making their short half-lives clinically irrelevant. For each day after the interruption of these medications, the $10-14 \%$ of normal platelet function is restored; so it takes 7 to 10 days for the entire platelet pool to be refurbished.

There is little evidence to guide platelet transfusion in major trauma patients on antiplatelet medications. A recent metaanalysis of six studies failed to demonstrate any clear benefit of platelet transfusions in patients with either spontaneous or traumatic intracranial haemorrhage [34]. In a retrospective analysis of a cohort of 113 patients with traumatic intracerebral haemorrhage $(\mathrm{TICH})$ on antiplatelet medications, Washington [35] et al., couldn't find any statistically significant difference in outcome between patients treated with platelets and those who were not transfused. Similar data were reported by Downey in a retrospective study involving two level 1 Trauma Centres over a 4 years period [36]. Ivascu [37] and Fortuna [38] in two separate studies observed a non significant trend towards higher mortality in patients with traumatic brain injury treated with platelets transfusion, but patients transfused were older and presented a lower GCS and higher ISS [35]. All of these studies though, have some weakness: they are retrospective, relative small and the indication and timing for platelet transfusion were not standardized. The timing of transfusion might play a key role as the haematoma may set up very early after trauma [39].

Despite the lack of evidence supporting the use of platelets, 
Nardi et al. Journal of Anesthesiology and Clinical Science 2013, http://www.hoajonline.com/journals/pdf/2049-9752-2-22.pdf

Table 4. The TASH-score (from Yücel N et al. J Trauma 2006).

\begin{tabular}{|c|c|c|}
\hline Variable & Value & Simplified score points \\
\hline \multirow[t]{5}{*}{ Hemoglobin $(\mathrm{mg} / \mathrm{dL})$} & $<7$ & 8 \\
\hline & $<9$ & 6 \\
\hline & $<10$ & 4 \\
\hline & $<11$ & 3 \\
\hline & $<12$ & 2 \\
\hline Intra abdominal free fluid & +ve FAST & 3 \\
\hline \multirow[t]{2}{*}{ Orthopedic fractures } & $\begin{array}{l}\text { Clinically unstable } \\
\text { pelvic fracture }\end{array}$ & 6 \\
\hline & $\begin{array}{l}\text { Femur fracture } \\
\text { (open/dislocated) }\end{array}$ & 3 \\
\hline \multirow[t]{3}{*}{ Base excess } & $<-10$ & 4 \\
\hline & $<-6$ & 3 \\
\hline & $<-2$ & 1 \\
\hline \multirow[t]{2}{*}{ Systolic blood pressure (mm Hg) } & $<100$ & 4 \\
\hline & $<120$ & 1 \\
\hline Heart rate (beat/min) & $\geq 120$ & 2 \\
\hline Sex & Male & 1 \\
\hline
\end{tabular}

many Institutions have implemented protocols for the reversal of platelet medications in the presence of $\mathrm{TICH}$. According to a multidisciplinary Institutional protocol published by Campbell, [40] 5 Units of platelets concentrate should be transfused right on admission to the patients on ASA who present with a small TICH. Patients on clopidogrel or with large $\mathrm{TICH}$ should receive 10 Units of platelets together with $0,3 \mathrm{mcg} / \mathrm{Kg}$ of desmopressin. As patients with major trauma and critical bleeding often require surgical or intravascular procedures that may be significantly affected by platelet dysfunction, many Authors recommend the use of platelet concentrates even in the absence of brain injury [41]. The ECS protocol endorses this strategy, recommending platelets for patients on antiplatelet drugs with critical bleeding and/or intracranial haemorrhage and/or undergoing emergency surgery. In patients with TICH on ASA therapy, we suggest the administration of 1 apheresis platelet concentrate (single donor) or 1 pool platelet concentrate (from pooling of 4-6 buffy coats). In patients with $\mathrm{TICH}$ or significant extracranial bleeding who are on ticlopidin, clopidogrel or dual antiplatelet drugs, we suggest the administration of 2 apheresis platelet concentrates or 2 pool platelet concentrates [42-44]. We also suggest to guide platelet transfusions with platelet function tests whereas available, if platelet dysfunction is documented [45].

Bleeding patients who are not on anticoagulants or antiplatelet drugs as well as those with ongoing bleeding in spite of a correct drug reversal, may need early coagulation support. Immediate identification of these cases is of paramount importance. Unfortunately clinical criteria as well as predictive scores have a lower than desirable predictive ability for massive transfusion. Predictive models of massive transfusion upon admission have been developed for this purpose. The Trauma Associated Severe Haemorrhage (TASH) score has been reported to have a high predictive value [46] and is widely used in Germany and other European countries. The TASH-score (Table 4) is based on a point-system taking into consideration clinical and laboratory data as well as the severity of injuries (orthopaedic fractures and intraabdominal fluid). In a multicenter study based on the data of the German Trauma Registry, Borgman [47] divided the population of trauma victims according to their TASH score. A TASH-score $\geq 15$ was associated with a $40 \%$ risk to receive a massive transfusion. Patients with a TASH-score $\geq 15$, had a high ISS $(42 \pm 15,4)$, and a mortality rate of $39.5 \%$. Patients of these groups who received a high plasma: $\mathrm{PRBC}$ ratio had a significantly lower mortality than those who received a lower ratio, although the two groups were not different for other confounders. Patients with a TASH-score $<15$ had a lower mortality (19.1\%) which was not further reduced by the aggressive administration of plasma. With all the limitations of a retrospective study, these data suggest that trauma patients who carry at least a $40 \%$ risk of massive transfusion according to the TASH-score, may benefit from an aggressive treatment with a high plasma:PRBCs ratio. However, the timely identification of patients who need aggressive haemostatic resuscitation remains challenging. In recent papers, Maegele [48] and Brockamp [49] used the German Trauma Society database to evaluate the predictive values for massive transfusion (MT) of six different scoring algorithms. Although the weighted and more complex systems such as the TASH score had the highest overall accuracy, more simple score as the one proposed by Vandromme [50], performed nearly as well. The Vandromme-score is based on 5 parameters four of which immediately available by clinical examination or by the generally available point of care devices: blood lactate $\geq 5 \mathrm{mmol} / \mathrm{L}$, heart rate $>105 \mathrm{bpm}$, INR $>1.5$, haemoglobin $\leq 11 \mathrm{~g} / \mathrm{l}$ and systolic blood pressure $<110 \mathrm{~mm}$ hg. Its predictive value for the need of massive transfusion increases with the number of positive parameters and the model with $\geq 3$ positive criteria showed a sensitivity of $53 \%$ and a specificity of $98 \%$. A major limitation of all models is their retrospective nature and the lack of prospective validation. It has been therefore suggested that individual triggers should be considered in order to improve the accuracy of the models [49]. An unpublished analysis of about 1700 major-trauma cases from the Italian Trauma Registry (RIT) showed that hypotension (SBP $\leq 90)$ on hospital admission is associated with a mortality rate as high as $50 \%$ mainly due to uncontrolled haemorrhage. However many hypothensive patients do not meet the MT criteria as they do not survive enough time to receive 10 Units of PRBCs. On the base of the analysis of the literature and of the data of the TUN trauma registries, the panel of experts suggested to activate the ECS protocol whenever a significant uncontrolled bleeding is associated with one or more of the following criteria: SBP 
$<100, \mathrm{BE}<-6$, Lactate $>5 \mathrm{mmol} / \mathrm{L}$, Haemoglobin $<9 \mathrm{gr} / \mathrm{dL}$ or a INR $>1,5$. The last criterion may be relevant in the case of patients referred from other hospitals with laboratory data showing an impaired coagulation. All these patients are expected to be transfused with universal blood soon after admission. Four Units of universal PRBCs is the standard package for emergency transfusion immediately available in the trauma bay of the TUN trauma centres.

The utility of the standard coagulation tests (eg., prothrombin time $[\mathrm{PT}]$, international normalized ratio [INR], activated partial tromboplastin time [aPTT], platelets count and fibrinogen [Clauss method]) to guide the acute haemostatic treatment in trauma patients with significant bleeding is limited. First, their results are inevitably delayed. In addition, because they are not performed on whole blood but on plasma, they cannot analyze the entire process of coagulation as it occurs in vivo. Moreover hyperfibrinolysis cannot be detected [51]. Rotational thromboelastometry (ROTEM) and thromboelastography (TEG) offer a quicker and more complete monitoring and allow a goal directed therapy. ROTEM, better than TEG, can also quickly detect fibrinolysis. Although the clear evidence of a positive impact on patients outcome is still missing, viscoelastic tests allow to distinguish the different haemostatic disorders following trauma, facilitating the proper management. The early use of thromboelastometry to guide treatment is recommended by the Austrian Guidelines [12]. As ROTEM or TEG are not always available at the moment in many Italian hospitals, the ECS protocol has been conceived without the obligatory guide of viscoelastic monitoring. However the panel acknowledges that viscoelastic monitoring may significantly improve the efficacy of the ECS protocol.

Brohi et al., recently observed that as many as $41 \%$ of the hypotensive trauma patients have fibrinogen level below $1.5 \mathrm{~g} / \mathrm{L}$ on hospital admission and its reduction is associated with the increasing base deficit [3]. A high percentage of the patients who meet the ECS criteria are therefore expected to have a low fibrinogen. According to the ECS protocol as soon as these patients start the transfusion with universal PRBCs they should receive an initial dose of $2 \mathrm{gr}$ of fibrinogen concentrate. In the Brohi's study patients who did not receive any source of fibrinogen had a reduction in fibrinogen level to $1.2 \mathrm{~g} / \mathrm{L}(1.0-1.8)$ as an average after the first 4 Units of PRBCs. The standard dose of $2 \mathrm{gr}$ of fibrinogen concentrate therefore aims to immediately provide the needed amount of fibrinogen to prevent its expected decrease following the first 4 Units of PRBCs [3]. Two grams of fibrinogen is approximately equal to the content of 4 plasma $(250 \mathrm{ml})$ Units. In a recent multicenter study in cardiac surgery Görlinger [53] demonstrated that a goal-directed therapy with fibrinogen concentrate and Point-of Care viscoelastic monitoring, was associated with a threefold reduction of intraoperative massive transfusion and a $90 \%$ reduction in the use of plasma. Although massive bleeding in trauma patients may have different underlying mechanisms than intra-operative bleeding, reducing the time to achieve effective coagulation support should be equally important. Fibrinogen plays a key role in clot formation and clot firmness because it is the final substrate of coagulation and the ligand of the platelet GPIIb/IIla receptors. Restoring or increasing fibrinogen levels may significantly contribute to improve the clotting process, control the bleeding and reduce the amount of transfused blood and plasma. In his retrospective study Schöchl showed that ROTEM guided haemostatic therapy with fibrinogen concentrate, was associated with a significant reduction in the number of patients requiring platelet transfusion and RBC transfusion, as compared with conventional treatment with plasma. However patients in both group required only 6 PRBCs Units as an average, thus the majority of them did not meet the MT definition. In truth Schöchl demonstrated that early coagulation support may effectively reduce the exposure of the bleeding trauma patients to allogeneic blood products, which is one of the goals of the ECS protocol.

In the daily practice of the TUN Trauma Centres a significant number of patients who eventually require less than 6 Units of PRBCs, receive plasma transfusion. Plasma is ordered in a fixed 1:1 ratio with PRBCs, immediately on arrival at the Emergency Room and immediately thawed in order to shorten the time-to treat. Fibrinogen concentrate may allow a little delay in the decision to thaw the plasma possibly reducing the waste of thawed plasma or inappropriate transfusion. Transfusion of plasma and platelets is independently associated with the development of multiple organ failure in critically injured patients. In a retrospective study on a large number of transfused patients requiring less than 10 Units of PRBC within 12 hours of admission, Inaba [9] observed a higher rate of complication in the patients receiving plasma. Patients receiving more than 6 Units of plasma had a 12 -fold increase in ARDS, 6-fold increase in MODS and 4-fold increase in pneumonia and sepsis with non significant improvement in survival. Johnson [11] confirmed these findings, but demonstrated that the deleterious effect associated with plasma transfusion outweighed the survival benefits of plasma only among patients receiving fewer than 6 Units of blood (PRBC). Therefore avoiding plasma transfusion in trauma patients who will not require at least 6 Units of PRBCs might be beneficial.

However fibrinogen concentrate does not provide volume expansion, hence higher amounts of crystalloids and/or colloids need to be infused to replace volume if a "plasma free" strategy is adopted. Crystalloids and more importantly, colloids significantly impair the clotting process, either by diluting clotting factors or directly impairing the clot strength. The potentially greater fluid infusion when concentrates are employed instead of plasma, may hamper the efficacy of this treatment strategy. This may explain the reason why, even in Schöchl series, a percentage of the bleeding patients still receive plasma. As no proper study have compared yet the 
"factor based" strategy with the "plasma based" approach this issue hasn't been settled. The rationale of the TUN protocol strategy is to provide a rapid support to the clotting process by the early administration of fibrinogen concentrate, with the aim to reduce plasma transfusion at least in patients who eventually will not need massive transfusion. These patients are the ones expected to get more harm than benefits from plasma.

Patients who continue to present significant a bleeding not withstanding early coagulation support and damage control surgery, will usually require more than 10 Units of PRBCs and meet the definition of massive transfusion (MT). Although data in the literature consistently show that early and aggressive plasma transfusion improve the survival of these patients, the optimal FFP/PRBC and PLT/PRBC ratio is controversial because of the possible survival bias flawing most studies [54,55]. A recent multicenter prospective study on a large population of patients undergoing MT showed that high FFP/PRBC and PLT/PRBC ratios are associated with a survival benefit also when time-dependency is accounted for [56].

The TUN expert committee feels there are still no enough evidence in the literature to adopt a "plasma free" strategy for the patients who require massive transfusion, for the following reasons: The pathophysiology of TIC is not yet [57] fully understood. Early coagulopathy (EC) occurring before hospital admission is caused mainly by tissue hypoperfusion and severe tissue injury. EC might have different causes than coagulopathy associated with haemodiluition, acidosis and hypothermia. Patients with tissue hypoperfusion and severe tissue damage have a strong activation of the protein $C$ pathway that seems to be associated with a depletion in PC levels and protein $C$ stores. This brings to increased levels of plasminogen activator inhibitor-1, favouring fibrinolyisis. Activated protein C also inactivates factor Va and factor VIIla [58] bringing to a significant consumption of factor $V$ and VIII. Coagulopathy caused by hypoperfusion is therefore characterized by an acquired deficit in coagulation factor $V$ (and by a less extent, VIII,VII,II,IX,X and XI [59]) together with a hyperfibrinolytic condition. Acidosis as a consequence of massive haemorrhage has a detrimental effect on the coagulation cascade; a low $\mathrm{pH}$ strongly affects the activity of factor VII and to a lesser extent factor X and factor V [60]. Moreover massive bleeding may cause also an acquired deficit of factor XIII which has an important role in clot stabilization and clot firmness. It has been suggested that a decreased factor $V$ activity as well as a deficit in factor XIII concentration might play a role in the pathogenesis of the early onset acute traumatic coagulopathy $[\mathbf{6 1 , 6 2}]$. Unfortunately factor XIII is available in some European country, but not in Italy. Some concern therefore has been raised about the potential risk of a "plasma free" strategy, as administration of plasma might play a role in restoring factor XIII levels and factor $V$ activity in the coagulopathic patients with severe hypoperfusion. It has been remarked that a level of factor $V$ as low as $5 \%$ still allows an effective coagulation in patients with hematologic diseases; however bleeding trauma patients might require higher levels.

In case of massive bleeding the restriction of plasma implies higher quantities of crystalloids and colloids for volume replacement. High volume of crystalloids may affect the haemostatic process through factors dilution and hypercloremic acidosis. The use of colloids has also been recently challenged as they cause fibrinogen dysfunction reducing the clot stability. In a recent randomized controlled study comparing saline with HES 130/0.4 for trauma resuscitation, patients in the HES group required significantly more blood and blood products [63]. Moreover it has been shown that the use of HES for fluid resuscitation is associated with a significantly higher complication rate if compared with normal saline [64]. Therefore volume replacement with colloids should probably be limited if not abandoned.

The panel agreed that additional data from controlled trials are needed before a pure "plasma free strategy" can be endorsed in the ECS protocol even for the patients requiring $\mathrm{MT}$. If a viscoelastic monitoring is available, the ECS protocol recommend to treat the patients who need MT with the administration of plasma with the addition of factors, following the goal-directed algorithm presented in Table 2. Treatment goals has been adapted from the AUVA Protocol [65] which is based on rotational thromboelastometry (ROTEM). Thromboelastography (TEG) might provide the same information. A treatment algorithm for TEG guided treatment has been proposed by Johansson et al., [66]. If ROTEM and TEG are not available, the ECS protocol recommends a standardized approach aimed to transfuse blood and plasma keeping the plasma/PRBCs ratio $\geq 1.5$ and to maintain platelets over 100.000 .

The economic impact of the ECS protocol has been one of the main concerns addressed by the panellists. Data from the Surgical and Trauma Intensive Care Units of the Insbruck University show that a goal directed coagulation management based on Point of Care monitoring and the use of factors brought to a sharp reduction in plasma transfusions (-88\%) and PRBCs requirement over a 5 years period [53]. The overall cost of blood products decreased by 200.000 Euro per year in spite of a significant increase in the cost of fibrinogen. However these results are referred to the general population of patients requiring transfusions, including patients undergoing elective cardiac surgery, therefore they might not be applicable to major bleeding in trauma victims. Fibrinogen concentrate is imported in Italy in limited amount provided authorization by the National Agency AIFA. One gram of fibrinogen costs around 400 Euro, thus the first step of the ECS protocol is associated with an estimated cost for fibrinogen concentrate of 800 Euros. The equivalent cost if plasma was used as the source of fibrinogen is difficult to calculate, because the cost of blood collection from blood donors cannot be easily quantified. However one Unit (200 mls) of industrial purified plasma, costs around 75 Euro. Therefore the estimated cost 
of $1000 \mathrm{mls}$ of commercial plasma, with a content of $2 \mathrm{~g}$ of fibrinogen, is 375 Euro. The additional cost of the TUN protocol strategy to reduce plasma transfusion in patients who eventually will not need massive transfusion have therefore been estimated in 425 Euro per patient. These patients are the ones expected to get more harm than benefits from plasma and the additional treatment cost should be balanced by the expected reduction in plasma related complications, ICU and hospital length of stay. The impact of the ECS protocol on the global treatment cost in case of massive transfusion, is even more complex to estimate also because an earlier support to the clotting process may reduce transfusion requirements as shown by Görlinger [53]. The TUN trauma centers that adopt the protocol will therefore carefully monitor financial aspects.

\section{Conclusion}

To meet the need of standardized the treatment of trauma patients with critical bleeding, the Italian trauma centers of the TUN network have developed a common therapeutic protocol called ECS. The protocol aims to avoid the use of plasma in the patients who will need a limited number of PRBCs, reduce the plasma related complications, and improve coagulation support in patients requiring massive transfusion through the early restoration of fibrinogen blood concentration. The ECS protocol has been developed assuming to have a point of care monitoring of coagulation, but can also be applied if a viscoelastic monitoring is not available. The ECS will be adopted by the TUN trauma centers with strict monitoring of economic impact and clinical results.

\section{Competing interests}

Before joining the panel all the panelists agreed to interrupt any professional relationships with organization that might held commercial interests in the topics. Neither the panel meetings nor the manuscript preparation have received financial or technical support. None of the Authors holds any stocks or shares in organization that may in any way gain or lose financially from the publication of this manuscript, either now or in the future. Here enclosed are listed all the potential competing interest related to the last five years :

GN is a member of the European ABC-T group in charge of develop and update the European Guidelines "Management of bleeding following major trauma" that is supported by an unrestricted grant from CSL Behring (in the past by Novo Nordisk). GN has received honoraria for consulting and lecturing from CSL Behring, honoraria for lecturing from Fresenius Kabi, research grant from Sangart, Institutional research grant from Novo-Nordisk. VA has received honoraria for lecturing from CSL Behring, BR, MGBo, SdB, $\mathrm{GBi}, \mathrm{OC}, \mathrm{EC}, \mathrm{EDB}, \mathrm{GG}, \mathrm{CC}, \mathrm{CP}, \mathrm{LT}$, AV these authors declare that they have no competing interests.

\section{Publication history}

Received: 04-Jan-2013 Revised: 20-Feb-2013

Accepted: 12-Apr-2013 Published: 06-May-2013

\section{Reference}

1. Brohi K, Singh J, Heron M and Coats T: Acute traumatic coagulopathy. J Trauma 2003, 54:1127-30. | Article | PubMed
2. Rossaint R, Bouillon B, Cerny V, Coats TJ, Duranteau J, FernandezMondejar E, Hunt BJ, Komadina R, Nardi G, Neugebauer E, Ozier Y, Riddez L, Schultz A, Stahel PF, Vincent JL and Spahn DR: Management of bleeding following major trauma: an updated European guideline. Crit Care 2010, 14:R52. | Article | PubMed Abstract | PubMed Full Text

3. Rourke C, Curry N, Khan S, Taylor R, Raza I, Davenport R, Stanworth S and Brohi K: Fibrinogen levels during trauma hemorrhage, response to replacement therapy, and association with patient outcomes. J Thromb Haemost 2012, 10:1342-51. | Article I PubMed

4. Stinger HK, Spinella PC, Perkins JG, Grathwohl KW, Salinas J, Martini WZ, Hess JR, Dubick MA, Simon CD, Beekley AC, Wolf SE, Wade CE and Holcomb JB: The ratio of fibrinogen to red cells transfused affects survival in casualties receiving massive transfusions at an army combat support hospital. J Trauma 2008, 64:S79-85; discussion S85. | Article | PubMed

5. Borgman MA, Spinella PC, Perkins JG, Grathwohl KW, Repine T, Beekley AC, Sebesta J, Jenkins D, Wade CE and Holcomb JB: The ratio of blood products transfused affects mortality in patients receiving massive transfusions at a combat support hospital. J Trauma 2007, 63:805-13. | Article I PubMed

6. Duchesne JC, Hunt JP, Wahl G, Marr AB, Wang YZ, Weintraub SE, Wright $\mathrm{MJ}$ and McSwain NE, Jr.: Review of current blood transfusions strategies in a mature level I trauma center: were we wrong for the last 60 years? J Trauma 2008, 65:272-6; discussion 276-8. | Article | PubMed

7. Davenport R, Curry N, Manson J, De'Ath H, Coates A, Rourke C, Pearse R, Stanworth $S$ and Brohi K: Hemostatic effects of fresh frozen plasma may be maximal at red cell ratios of 1:2. J Trauma 2011, 70:90-5; discussion 95-6. | Article | PubMed

8. Snyder CW, Weinberg JA, McGwin G, Jr., Melton SM, George RL, Reiff DA, Cross JM, Hubbard-Brown J, Rue LW, 3rd and Kerby JD: The relationship of blood product ratio to mortality: survival benefit or survival bias? J Trauma 2009, 66:358-62; discussion 362-4. | Article | PubMed

9. Inaba K, Branco BC, Rhee P, Blackbourne LH, Holcomb JB, Teixeira PG, Shulman I, Nelson J and Demetriades D: Impact of plasma transfusion in trauma patients who do not require massive transfusion. J Am Coll Surg 2010, 210:957-65. | Article | PubMed

10. Pandey $S$ and Vyas GN: Adverse effects of plasma transfusion. Transfusion 2012, 52 Suppl 1:65S-79S. | Article | PubMed

11. Johnson JL, Moore EE, Kashuk JL, Banerjee A, Cothren CC, Biffl WL and Sauaia A: Effect of blood products transfusion on the development of postinjury multiple organ failure. Arch Surg 2010, 145:973-7. | Article | PubMed

12. Fries D, Innerhofer P, Perger P, Gutl M, Heil S, Hofmann N, Kneifel W, Neuner L, Pernerstorfer T, Pfanner G, Schochl H, Ziegler B, Kolblinger C and Kozek-Langenecker S: [Coagulation management in trauma-related massive bleeding. - Recommendations of the Task Force for Coagulation (AGPG) of the Austrian Society of Anesthesiology, Resuscitation and Intensive Care Medicine (OGARI)]. Anasthesiol Intensivmed Notfallmed Schmerzther 2010, 45:552-61. | Article | PubMed

13. Schochl H, Nienaber U, Hofer G, Voelckel W, Jambor C, Scharbert G, Kozek-Langenecker S and Solomon C: Goal-directed coagulation management of major trauma patients using thromboelastometry (ROTEM)-guided administration of fibrinogen concentrate and prothrombin complex concentrate. Crit Care 2010, 14:R55. | Article | PubMed Abstract | PubMed Full Text

14. Nienaber $U$, Innerhofer P, Westermann I, SchochI H, Attal R, Breitkopf $R$ and Maegele $M$ : The impact of fresh frozen plasma vs coagulation factor concentrates on morbidity and mortality in trauma-associated haemorrhage and massive transfusion. Injury 2011, 42:697-701. | Article | PubMed

15. Shakur H, Roberts I, Bautista R, Caballero J, Coats T, Dewan Y, El-Sayed H, Gogichaishvili T, Gupta S, Herrera J, Hunt B, Iribhogbe P, Izurieta M, Khamis H, Komolafe E, Marrero MA, Mejia-Mantilla J, Miranda J, Morales C, Olaomi O, Olldashi F, Perel P, Peto R, Ramana PV, Ravi RR and Yutthakasemsunt S: Effects of tranexamic acid on death, vascular occlusive events, and blood transfusion in trauma patients with significant haemorrhage (CRASH-2): a randomised, placebo-controlled trial. Lancet 2010, 376:23-32. | Article | PubMed 
Nardi et al. Journal of Anesthesiology and Clinical Science 2013, http://www.hoajonline.com/journals/pdf/2049-9752-2-22.pdf

16. Dossett LA, Riesel JN, Griffin MR and Cotton BA: Prevalence and implications of preinjury warfarin use: an analysis of the National Trauma Databank. Arch Surg 2011, 146:565-70. | Article | PubMed

17. Guyatt GH, AkI EA, Crowther M, Gutterman DD and Schuunemann $\mathrm{HJ}$ : Executive summary: Antithrombotic Therapy and Prevention of Thrombosis, 9th ed: American College of Chest Physicians EvidenceBased Clinical Practice Guidelines. Chest 2012, 141:7S-47S. | Article | PubMed Abstract | PubMed Full Text

18. Holbrook A, Schulman S, Witt DM, Vandvik PO, Fish J, Kovacs MJ, Svensson PJ, Veenstra DL, Crowther M and Guyatt GH: Evidence-based management of anticoagulant therapy: Antithrombotic Therapy and Prevention of Thrombosis, 9th ed: American College of Chest Physicians Evidence-Based Clinical Practice Guidelines. Chest 2012, 141:e152S-84S. | Article | PubMed Abstract | PubMed Full Text

19. Keeling D, Baglin T, Tait C, Watson H, Perry D, Baglin C, Kitchen S and Makris M: Guidelines on oral anticoagulation with warfarin - fourth edition. BrJ Haematol 2011, 154:311-24. | Article | PubMed

20. Appelboam $R$ and Thomas EO: Warfarin and intracranial haemorrhage. Blood Rev 2009, 23:1-9. | Article | PubMed

21. McMillian WD and Rogers FB: Management of prehospital antiplatelet and anticoagulant therapy in traumatic head injury: a review. J Trauma 2009, 66:942-50. | Article | PubMed

22. Chapman SA, Irwin ED, Beal AL, Kulinski NM, Hutson KE and Thorson MA: Prothrombin complex concentrate versus standard therapies for INR reversal in trauma patients receiving warfarin. Ann Pharmacother 2011, 45:869-75. | Article | PubMed

23. Imberti D, Barillari G, Biasioli C, Bianchi M, Contino L, Duce R, D'Inca M, Mameli L, Pinna L and Ageno W: Prothrombin complex concentrates for urgent anticoagulation reversal in patients with intracranial haemorrhage. Pathophysiol Haemost Thromb 2008, 36:259-65. | Article I PubMed

24. Pernod G, Godier A, Gozalo C, Tremey B and Sie P: French clinical practice guidelines on the management of patients on vitamin $K$ antagonists in at-risk situations (overdose, risk of bleeding, and active bleeding). Thromb Res 2010, 126:e167-74. | Article | PubMed

25. Prisco D. Terapia anticoagulante orale, chirurgia e manovre invasive. Raccomandazioni della Federazione Centri per la Diagnosi della Trombosi e Sorveglianza della Terapie Antitrombotiche. 2005 Raccomandazioni FCSA. | Website

26. Weitz JI: New oral anticoagulants: a view from the laboratory. $A m \mathrm{~J}$ Hematol 2012, 87 Suppl 1:S133-6.| Article | PubMed

27. Brem E, Koyfman A and Foran M: Review of Recently Approved Alternatives to Anticoagulation with Warfarin for Emergency Clinicians. J Emerg Med 2013. | Article | PubMed

28. Schulman S and Crowther MA: How I treat with anticoagulants in 2012: new and old anticoagulants, and when and how to switch. Blood 2012, 119:3016-23. | Article | PubMed

29. Eerenberg ES, Kamphuisen PW, Sijpkens MK, Meijers JC, Buller HR and Levi M: Reversal of rivaroxaban and dabigatran by prothrombin complex concentrate: a randomized, placebo-controlled, crossover study in healthy subjects. Circulation 2011, 124:1573-9. | Article | PubMed

30. Dzik WS: Reversal of drug-induced anticoagulation: old solutions and new problems. Transfusion 2012, 52 Suppl 1:45S-55S. | Article | PubMed

31. Kaatz S, Kouides PA, Garcia DA, Spyropolous AC, Crowther M, Douketis JD, Chan AK, James A, Moll S, Ortel TL, Van Cott EM and Ansell J: Guidance on the emergent reversal of oral thrombin and factor $\mathrm{Xa}$ inhibitors. Am J Hematol 2012, 87 Suppl 1:S141-5. | Article | PubMed

32. Obeng-Gyasi S, Loor MM, Samotowka MA and Moorman ML: Management of dabigatran-induced anticoagulation in trauma and acute care surgery patients. J Trauma Acute Care Surg 2012, 73:1064-9. | Article | PubMed

33. Pengo V, Crippa L, Falanga A, Finazzi G, Marongiu F, Palareti L, Poli D, Testa S, Tiraferri E, Tosetto A, Tripodi A, Manotti C. Thromb Haemost 2011, 106:868-876.

34. Batchelor JS and Grayson A: A meta-analysis to determine the effect on survival of platelet transfusions in patients with either spontaneous or traumatic antiplatelet medication-associated intracranial haemorrhage. BMJ Open 2012, 2:e000588. | Article | PubMed Abstract | PubMed Full Text

35. Washington CW, Schuerer DJ and Grubb RL, Jr.: Platelet transfusion: an unnecessary risk for mild traumatic brain injury patients on antiplatelet therapy. J Trauma 2011, 71:358-63. | Article | PubMed

36. Downey DM, Monson B, Butler KL, Fortuna GR, Jr., Saxe JM, Dolan $J P$, Markert RJ and McCarthy MC: Does platelet administration affect mortality in elderly head-injured patients taking antiplatelet medications? Am Surg 2009, 75:1100-3. | Article | PubMed

37. Ivascu FA, Howells GA, Junn FS, Bair HA, Bendick PJ and Janczyk RJ: Predictors of mortality in trauma patients with intracranial hemorrhage on preinjury aspirin or clopidogrel. J Trauma 2008, 65:785-8. | Article | PubMed

38. Fortuna GR, Mueller EW, James LE, Shutter LA and Butler KL: The impact of preinjury antiplatelet and anticoagulant pharmacotherapy on outcomes in elderly patients with hemorrhagic brain injury. Surgery 2008, 144:598-603; discussion 603-5. I Article | PubMed

39. Naidech AM, Liebling SM, Rosenberg NF, Lindholm PF, Bernstein RA, Batjer HH, Alberts MJ and Kwaan HC: Early platelet transfusion improves platelet activity and may improve outcomes after intracerebral hemorrhage. Neurocrit Care 2012, 16:82-7. | Article | PubMed

40. Campbell PG, Sen A, Yadla S, Jabbour P and Jallo J: Emergency reversal of antiplatelet agents in patients presenting with an intracranial hemorrhage: a clinical review. World Neurosurg 2010, 74:279-85. | Article I PubMed

41. BCSH Guidelines for the use of platelet transfusions. BJH 2003, 122 : 10-23. I Website

42. Sarode R: How do I transfuse platelets (PLTs) to reverse anti-PLT drug effect? Transfusion 2012, 52:695-701; quiz 694. | Article | PubMed

43. Vilahur G, Choi BG, Zafar MU, Viles-Gonzalez JF, Vorchheimer DA, Fuster $\mathrm{V}$ and Badimon JJ: Normalization of platelet reactivity in clopidogreltreated subjects. J Thromb Haemost 2007, 5:82-90. | Article | PubMed

44. Tosetto A, Balduini CL, Cattaneo M, De Candia E, Mariani G, Molinari AC, Rossi E and Siragusa S: Management of bleeding and of invasive procedures in patients with platelet disorders and/or thrombocytopenia: Guidelines of the Italian Society for Haemostasis and Thrombosis (SISET). Thromb Res 2009, 124:e13-8. | Article | PubMed

45. Harrison P, Frelinger AL, 3rd, Furman MI and Michelson AD: Measuring antiplatelet drug effects in the laboratory. Thromb Res 2007, 120:32336. | Article | PubMed

46. Yucel $N$, Lefering $R$, Maegele $M$, Vorweg $M$, Tjardes $T$, Ruchholtz $S$, Neugebauer EA, Wappler F, Bouillon B and Rixen D: Trauma Associated Severe Hemorrhage (TASH)-Score: probability of mass transfusion as surrogate for life threatening hemorrhage after multiple trauma. $J$ Trauma 2006, 60:1228-36; discussion 1236-7. | Article | PubMed

47. Borgman MA, Spinella PC, Holcomb JB, Blackbourne LH, Wade CE, Lefering $R$, Bouillon $B$ and Maegele M: The effect of FFP:RBC ratio on morbidity and mortality in trauma patients based on transfusion prediction score. Vox Sang 2011, 101:44-54. | Article | PubMed Abstract I PubMed Full Text

48. Maegele M, Brockamp T, Nienaber U, Probst C, Schoechl H, Gorlinger $\mathrm{K}$ and Spinella P: Predictive Models and Algorithms for the Need of Transfusion Including Massive Transfusion in Severely Injured Patients. Transfus Med Hemother 2012, 39:85-97. | Article | PubMed Abstract | PubMed Full Text

49. Brockamp T, Nienaber U, Mutschler M, Wafaisade A, Peiniger S, Lefering $R$, Bouillon $B$ and Maegele $M$ : Predicting on-going hemorrhage and transfusion requirement after severe trauma: a validation of six scoring systems and algorithms on the TraumaRegister DGU(R). Crit Care 2012, 16:R129. | Article | PubMed Abstract | PubMed Full Text

50. Vandromme MJ, Griffin RL, McGwin G, Jr., Weinberg JA, Rue LW, 3rd and Kerby JD: Prospective identification of patients at risk for massive transfusion: an imprecise endeavor. Am Surg 2011, 77:155-61. | Article I PubMed 
51. Theusinger OM, Wanner GA, Emmert MY, Billeter A, Eismon J, Seifert B, Simmen HP, Spahn DR and Baulig W: Hyperfibrinolysis diagnosed by rotational thromboelastometry (ROTEM) is associated with higher mortality in patients with severe trauma. Anesth Analg 2011, 113:100312. | Article | PubMed

52. Recommendations of the working group on Perioperative Coagulation of the ÖGARI: Coagulation management in trauma-related massive bleeding.

53. Gorlinger K, Fries D, Dirkmann D, Weber CF, Hanke AA and Schochl H: Reduction of Fresh Frozen Plasma Requirements by Perioperative Pointof-Care Coagulation Management with Early Calculated Goal-Directed Therapy. Transfus Med Hemother 2012, 39:104-113. | Article | PubMed Abstract I PubMed Full Text

54. Snyder CW, Weinberg JA, McGwin G, Jr., Melton SM, George RL, Reiff DA, Cross JM, Hubbard-Brown J, Rue LW, 3rd and Kerby JD: The relationship of blood product ratio to mortality: survival benefit or survival bias? J Trauma 2009, 66:358-62; discussion 362-4. | Article | PubMed

55. Ho AM, Dion PW, Yeung JH, Holcomb JB, Critchley LA, Ng CS, Karmakar $\mathrm{MK}$, Cheung $\mathrm{CW}$ and Rainer TH: Prevalence of survivor bias in observational studies on fresh frozen plasma:erythrocyte ratios in trauma requiring massive transfusion. Anesthesiology 2012, 116:716-28. | Article | PubMed

56. Brown JB, Cohen MJ, Minei JP, Maier RV, West MA, Billiar TR, Peitzman $A B$, Moore EE, Cushieri I and Sperry JL: Debunking the survival bias myth: characterization of mortality during the initial 24 hours for patients requiring massive transfusion. J Trauma Acute Care Surg 2012, 73:358-64; discussion 364. | Article | PubMed

57. Cohen MJ, Call M, Nelson M, Calfee CS, Esmon CT, Brohi K and Pittet JF: Critical role of activated protein $\mathrm{C}$ in early coagulopathy and later organ failure, infection and death in trauma patients. Ann Surg 2012, 255:37985. | Article | PubMed Abstract | PubMed Full Text

58. Theusinger OM, Madjdpour C and Spahn DR: Resuscitation and transfusion management in trauma patients: emerging concepts. Curr Opin Crit Care 2012, 18:661-70. | Article | PubMed

59. Jansen JO, Scarpelini S, Pinto R, Tien HC, Callum J and Rizoli SB: Hypoperfusion in severely injured trauma patients is associated with reduced coagulation factor activity. J Trauma 2011, 71:S435-40. | Article I PubMed

60. Duchesne JC, McSwain NE, Jr., Cotton BA, Hunt JP, Dellavolpe J, Lafaro K, Marr AB, Gonzalez EA, Phelan HA, Bilski T, Greiffenstein P, Barbeau JM, Rennie KV, Baker CC, Brohi K, Jenkins DH and Rotondo M: Damage control resuscitation: the new face of damage control. J Trauma 2010, 69:976-90. | Article | PubMed

61. Cohen MJ and West M: Acute traumatic coagulopathy: from endogenous acute coagulopathy to systemic acquired coagulopathy and back. J Trauma 2011, 70:S47-9. | Article | PubMed

62. Dirkmann D, Gorlinger K, Gisbertz C, Dusse F and Peters J: Factor XIII and tranexamic acid but not recombinant factor VIla attenuate tissue plasminogen activator-induced hyperfibrinolysis in human whole blood. Anesth Analg 2012, 114:1182-8. | Article | PubMed

63. James MF, Michell WL, Joubert IA, Nicol AJ, Navsaria PH and Gillespie RS: Resuscitation with hydroxyethyl starch improves renal function and lactate clearance in penetrating trauma in a randomized controlled study: the FIRST trial (Fluids in Resuscitation of Severe Trauma). Br J Anaesth 2011, 107:693-702.| Article | PubMed

64. Myburgh JA, Finfer S, Bellomo R, Billot L, Cass A, Gattas D, Glass $P$, Lipman J, Liu B, McArthur C, McGuinness S, Rajbhandari D, Taylor CB and Webb SA: Hydroxyethyl starch or saline for fluid resuscitation in intensive care. N Engl J Med 2012, 367:1901-11. | Article | PubMed

65. Schochl H, Maegele M, Solomon C, Gorlinger K and Voelckel W: Early and individualized goal-directed therapy for trauma-induced coagulopathy. Scand J Trauma Resusc Emerg Med 2012, 20:15. | Article | PubMed Abstract | PubMed Full Text

66. Johansson PI and Stensballe J: Effect of Haemostatic Control Resuscitation on mortality in massively bleeding patients: a before and after study. Vox Sang 2009, 96:111-8. | Article | PubMed Abstract | PubMed Full Text
Citation:

Nardi G, Agostini V, Rondinelli BM, Bocci G, Di Bartolomeo S, Bini G, Chiara O, Cingolani E, De Blasio E, Gordini G, Coniglio C, Pellegrin $\mathrm{C}$, Targa L and Volpi A: Prevention and treatment of trauma induced coagulopathy (TIC). An intended protocol from the Italian trauma update research group. journal of Anesthesiology and Clinical Science 2013, 2:22.

http://dx.doi.org/10.7243/2049-9752-2-22 